\title{
Pour en lire plus : L'écologie vue du Sud
}

Mohammed Taleb (2014). L'écologie vue du Sud. Paris : Éditions Sang de

la Terre, $254 \mathrm{p}$.

\section{Nathalie Calmé}

\section{OpenEdition}

\section{Journals}

Édition électronique

URL : http://journals.openedition.org/ere/587

DOI : $10.4000 /$ ere.587

ISSN : 2561-2271

Éditeur

Centr'ERE

Édition imprimée

Date de publication : 1 septembre 2016

ISSN : 1373-9689

Référence électronique

Nathalie Calmé, « Pour en lire plus : L'écologie vue du Sud », Éducation relative à l'environnement [En ligne], Volume 13 - 1 | 2016, mis en ligne le 15 septembre 2016, consulté le 24 septembre 2020. URL http://journals.openedition.org/ere/587 ; DOI : https://doi.org/10.4000/ere.587 


\section{Pour en lire plus : L'écologie vue du Sud}

Mohammed Taleb (2014). L'écologie vue du Sud. Paris : Éditions Sang de la Terre, $254 \mathrm{p}$.

\section{Nathalie Calmé}

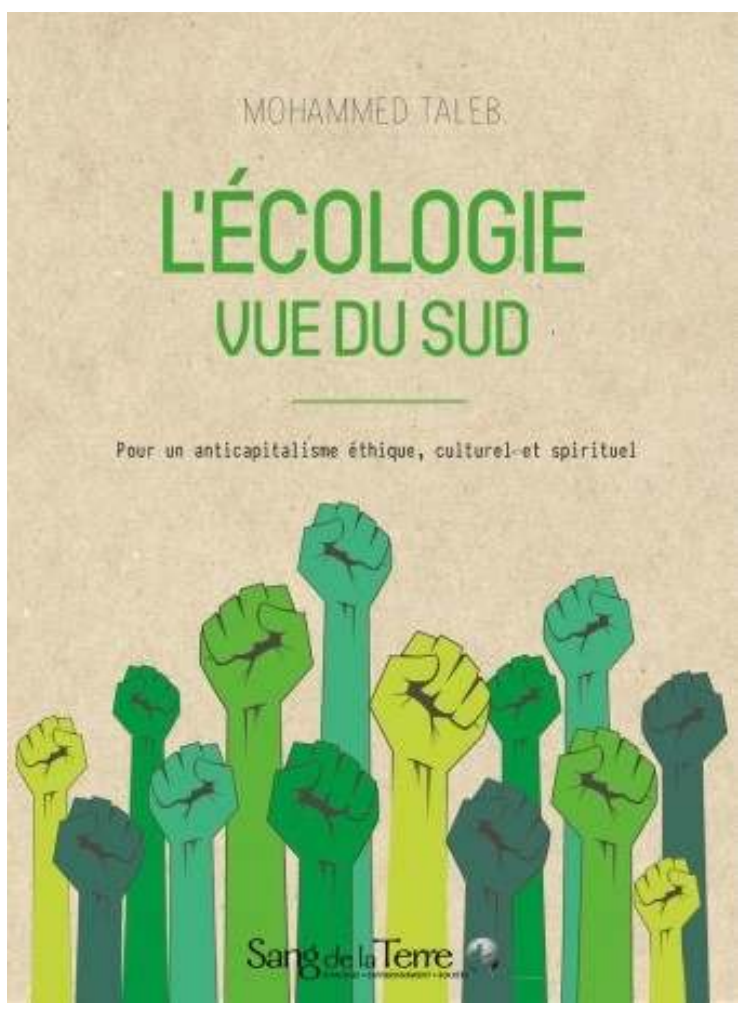

1 Si l'écologie est bel et bien une quête universelle, un défi planétaire, cette universalité a souvent été, et c'est encore largement le cas aujourd'hui, confisquée et monopolisée par l'Occident. Le philosophe algérien Mohammed Taleb qui enseigne l'écopsychologie à Lausanne et qui est formateur en éducation relative à l'environnement nous offre 
avec son livre une exploration fouillée de l'écologie telle qu'elle est pensée et pratiquée dans les pays des trois A (Asie, Afrique et Amérique latino-afro-indienne).

2 S'inscrivant dans les perspectives philosophiques ouvertes par Frantz Fanon, Leonardo Boff, Edward Said, Rabindranath Tagore, Karl Marx, Alfred North Whitehead, Gilbert Durand, ou encore James Hillman, Mohammed Taleb met l'accent sur deux grandes différences entre l'écologie du Sud et celle du Nord. La première est une différence de classe : au Nord, l'écologie est prise en charge principalement par les classes moyennes, souvent supérieures, celles qui ont réglé la question de la reproduction matérielle de l'existence. Au Sud, elle est principalement l'affaire des couches populaires, aussi bien celles qui vivent dans le monde rural dans une situation de dépossession foncière (les fameux "sans terre ", qu'ils soient Brésiliens ou Indiens), que dans le monde urbain, dans une situation de précarité socio-économique. La présence des peuples autochtones dans les batailles écologiques confirment cette dimension populaire de l'écologie.

La seconde différence, pointée par Mohammed Taleb, est relative à la perception de l'environnement par les écologies du Sud et du Nord. Et la question du Développement durable vient manifester cette différence. Il écrit ainsi : "Disons-le dès maintenant, le développement durable est l'une des formes de l'écologie occidentale. [...] L'environnement réduit à un ensemble de ressources matérielles, la gestion environnementale et la croissance verte sont les seuls outils que ce développement se donne. Son approche est clairement technocratique, technoscientifique, économiciste. Elle occulte la profondeur historique de la crise écologique, en même temps qu'elle réprime toutes les écologies dissidentes. » En parcourant les chapitres de ce livre, on se rend compte de l'importance accordée à la dimension culturelle et spirituelle dans la conscientisation verte ou dans les luttes paysannes et écopaysannes.

Cet ouvrage L'écologie vue du Sud est structuré en six chapitres :

1. Mobilisations paysannes indiennes contre la dépossession: La dimension cosmique de la culture indienne; Fleuves sacrés; Montagnes et forêts spirituelles; L'écologie des Adivasis; Rabindranath Tagore ; Entre tradition, modernité et néolibéralisme ; Ces paysans suicidés ; Les chemins de la résistance et de l'alternative ; De Chipko à la Narmada ; Vandana Shiva, la Navdanya et l'écologie sacrée.

2. Le Paysan sans terre, figure archétypale de la résistance dans l'Amérique latino-afro-indienne: La poésie écologique de José Marti ; La crise socio-environnementale du Brésil ; La Commission Pastorale pour la Terre ; Le MST, mouvement des Travailleurs Ruraux Sans Terre ; Écologie et anti-impérialisme ; «Lutter et construire la réforme agraire populaire!»; L'éducation populaire du MST pour l'agroécologie et l'environnement; Coopératives, semences et biodiversité ; Le MST, l'écologie brésilienne et le mouvement écopaysan international ; Chico Mendes, héros de l'Amazonie et martyr de la paysannerie.

3. Les Nations indiennes aux États-Unis: cosmovision politique et militance sacrée: À l'assaut d'Alcatraz; American Indian Movement et Wounded Knee ; L'affaire Leonard Peltier ; Une voix indienne dans le monde.

4. Palestine : le Peuple et la Terre face à l'occupation israélienne : La catastrophe écologique de 1948 ; La parole vitaliste des poètes; L'État d'Israël : nature coloniale et guerres contre l'environnement ; Le combat pour la terre de la militance arabe palestinienne ; La journée de la Terre: insurrection paysanne en Palestine occupée; Dynamiques palestiniennes de résistance socioécologique; L'écologie du Sud au chevet de la Palestine.

5. Une Afrique en lutte sur le front écologique: L'écologie de l'âme africaine; L'intensité d'une crise; Sankara, le président de l'eau, de l'arbre et de la vie; Dynamiques paysannes et mouvements de la société civile africaine ; Un conte. 
6. Philosophie et théologie de la libération écosociale : Écologie, spiritualité et justice sociale : les contributions de Faycal Yachir ; La parole de résistance des peuples autochtones; Un islam cosmique de résistance ; Le visage chrétien de la libération écosociale

5 Conclusion. Quelles confluences avec l'écologie vue du Nord? : Les conditions du dialogue ; Écosocialisme; Féminisme anti-impérialiste, écologique et spirituel; Décroissance; Écologie sociale et libertaire ; Pour un universalisme pluriel.

6 Le livre comprend également une importante annexe composée de textes de mouvements écologistes, écopaysans, et alterglobalistes du Sud, ainsi qu'un carnet d'adresses.

Pour information : lesingulieruniversel@yahoo.fr

\section{AUTEUR}

\section{NATHALIE CALMÉ}

Écrivaine et journaliste 